\title{
Comparison of Vaisala radiosondes RS41 and RS92 launched over the oceans from the Arctic to the tropics
}

\author{
Yoshimi Kawai $^{1}$, Masaki Katsumata ${ }^{1}$, Kazuhiro Oshima ${ }^{2}$, Masatake E. Hori ${ }^{2}$, and Jun Inoue ${ }^{3}$ \\ ${ }^{1}$ Research and Development Center for Global Change, Japan Agency for Marine-Earth Science and Technology, \\ Yokosuka 237-0061, Japan \\ ${ }^{2}$ Institute of Arctic Climate and Environment Research, Japan Agency for Marine-Earth Science and Technology, \\ Yokosuka 237-0061, Japan \\ ${ }^{3}$ Arctic Environment Research Center, National Institute of Polar Research, Tachikawa 190-8518, Japan \\ Correspondence to: Yoshimi Kawai (ykawai@jamstec.go.jp)
}

Received: 15 February 2017 - Discussion started: 29 March 2017

Revised: 31 May 2017 - Accepted: 5 June 2017 - Published: 14 July 2017

\begin{abstract}
To assess the differences between the RS92 radiosonde and its improved counterpart, the Vaisala RS41SGP radiosonde version with a pressure sensor, 36 twinradiosonde launches were made over the Arctic Ocean, Bering Sea, western North Pacific Ocean, and the tropical Indian Ocean during two cruises of R/V Mirai in 2015. The biases, standard deviations, and root mean squares (rms's) of the differences between the RS41 and RS92 data over all flights and altitudes were smaller than the nominal combined uncertainties of the RS41, except that the rms of the differences of pressure above 100 exceeded $0.6 \mathrm{hPa}$. A comparison between daytime and nighttime flights in the tropics revealed that the pressure difference was systematically larger during the day than at night above an altitude of $4.5 \mathrm{~km}$, suggesting that there was some effect of solar heating on the pressure measurements, but the exact reason is unclear. The agreement between the RS41 and RS92 temperature measurements was better than the combined uncertainties. However, there were some noteworthy discrepancies presumably caused by the "wet-bulbing" effect on the RS92 radiosonde and the stagnation of the balloon. Although the median of the relative humidity differences was only a little more than $2 \%$ of the relative humidity at all altitudes, the relative humidity of the RS92 was much lower than that of the RS41 at altitudes of about $17 \mathrm{~km}$ in the tropics. This dry bias might have been caused by the incomplete solar radiation correction of the RS92, and a correction table for the daytime RS92 humidity was calculated. This study showed that the RS41 measurements were consistent with the specifications of the
\end{abstract}

manufacturer in most cases over both the tropical and polar oceans. However, further studies on the causes of the discrepancies are needed.

\section{Introduction}

Radiosonde observations are operationally conducted twice a day at about 800 sites throughout the world. Radiosondes measure temperature, humidity, wind velocities, and pressure (or height) in the troposphere and stratosphere. They ascend through the atmosphere attached to balloons filled with helium or hydrogen gas. The data are sent to the Global Telecommunication System and are used for data assimilation in real-time operational weather forecast systems, atmospheric reanalyses, and climate models. In situ aerological observations are also indispensable for validating satellitederived meteorological data (e.g., Fujita et al., 2008); for assessing long-term trends in the upper atmosphere (e.g., Thorne et al., 2005; Maturilli and Kayser, 2016); and for other meteorological research, including assimilation experiments and air-sea interaction studies (e.g., Inoue et al., 2013, 2015; Kawai et al., 2014). Efforts to improve the quality of radiosonde data have continued to the present time (e.g., Ciesielski et al., 2014; Bodeker et al., 2016). One consequence of the technological advancements has been the need to account for accuracy differences following radiosonde upgrades in the long-term continuous datasets (Wang et al., 2013). 

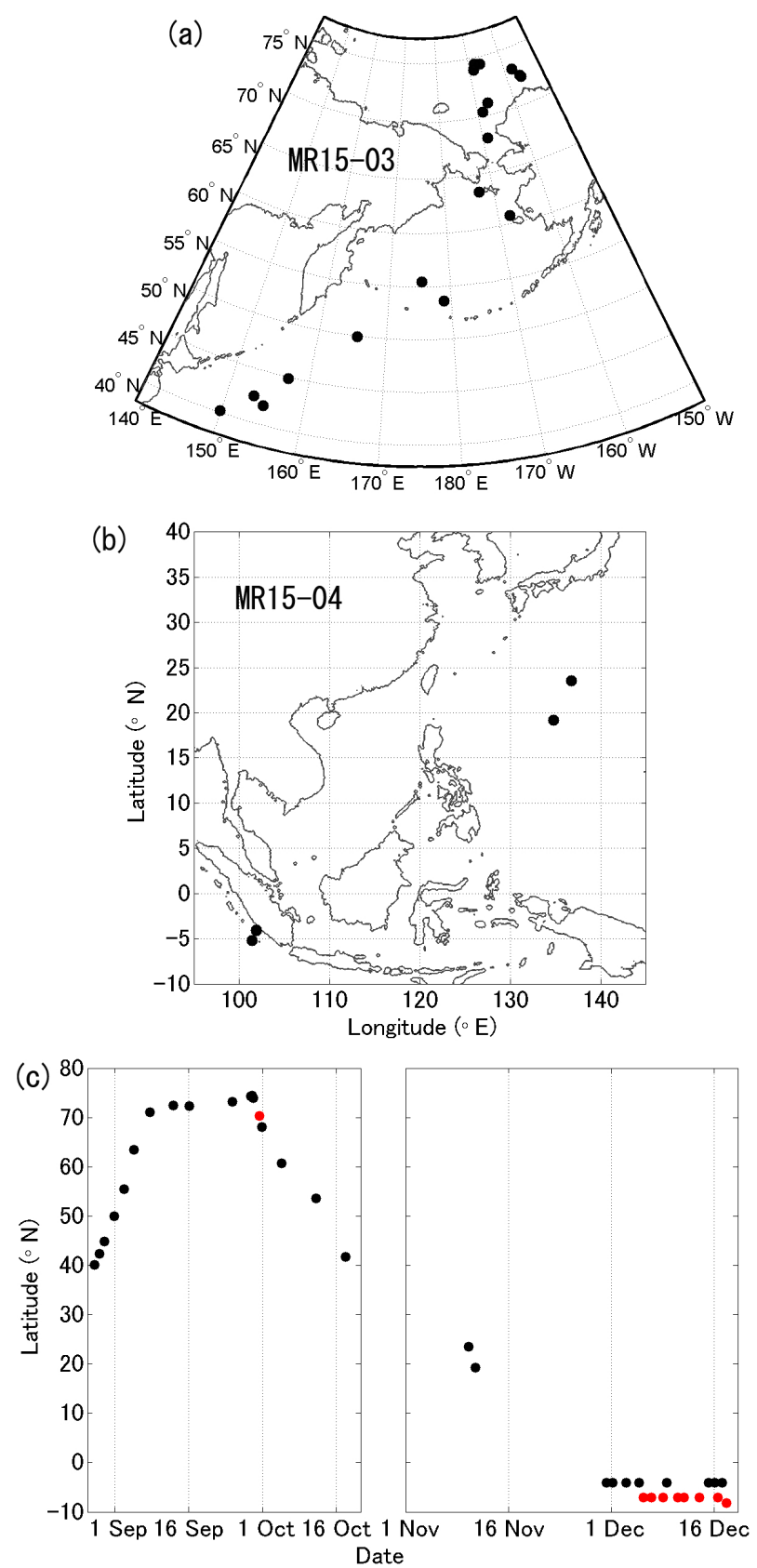

Figure 1. Positions of the twin-radiosonde launches during the (a) MR15-03 cruise and (b) MR15-04 cruise. (c) Time-latitude diagram of the launches. Black and red dots represent daytime and nighttime soundings, respectively. The red dots in December are plotted with a shift of $3^{\circ}$ latitude.

The model RS92 radiosonde manufactured by Vaisala Ltd., which was first introduced in 2003, has been used throughout the world, and it is now being replaced with a successor model, the RS41 (Table 1). To clarify the differences between the RS41 and RS92 radiosondes, intercomparison experiments have already been carried out at several sites on land from high latitudes to the tropics (Motl,
2014; Jauhiainen et al., 2014; Jensen et al., 2016). Jauhiainen et al. (2014) have reported results of comparisons in several countries, including Finland, the United Kingdom, the Czech Republic, and Malaysia. They reported that the RS41 radiosonde was a consistent improvement over the RS92 in terms of reproducibility with respect to temperature and humidity under both day and night conditions. A different intercomparison study was carried out at a site in Oklahoma, USA, by Jensen et al. (2016). They showed that the RS92 and RS41 measurements agreed much better than the manufacturer-specified combined uncertainties. Their results also indicated that the RS41 measurements of temperature and humidity appeared to be less sensitive to solar heating than those made with the RS92.

The accuracy of the pressure measured with the model RS41-SGP, however, has not yet been examined, nor has a comparison been made between the RS41 and RS92 radiosondes in the marine atmosphere. Unlike the atmosphere over land, the marine atmosphere is less affected by topography and the greater temperature variations of the land surface. As a result, phenomena such as convection and precipitation and their diurnal cycles over the oceans are different from those over land (e.g., Yang and Slingo, 2001; Minobe and Takebayashi, 2015). We performed a total of 36 intercomparison flights during two cruises of R/V Mirai of the Japan Agency for Marine-Earth Science and Technology (JAMSTEC) in 2015. Our observations covered a wide range of latitudes over the oceans, an important consideration from the standpoint of confirming the performance of the RS41. We describe the cruises and the methodology of the intercomparison observations in Sect. 2. Section 3 shows the results of the comparisons. In Sect. 4, we focus on the data obtained in the tropics and further discuss the reasons for the differences between the RS41 and RS92 results. Section 5 is a summary of the study.

\section{Intercomparison experiment}

\subsection{Cruises}

The intercomparison observations were performed by launching both the RS41 and RS92 radiosondes tied to one balloon (referred to as a "twin-radiosonde" flight) during the MR15-03 and MR15-04 cruises of R/V Mirai. In the case of the MR15-03 cruise, the vessel departed from Hachinohe, Japan, on 26 August; cruised the Arctic Ocean from 6 September to 3 October (JAMSTEC, 2015); and returned to Hachinohe on 21 October. The twin-radiosonde flights were launched nine times in the Chukchi Sea, four times in the Bering Sea, and five times in the western North Pacific (Fig. 1a and Table 2). The MR15-04 cruise was for tropical meteorological research, and the vessel stayed near $4^{\circ} 04^{\prime} \mathrm{S}$, $101^{\circ} 54^{\prime} \mathrm{E}$ off Bengkulu, west of Sumatra Island, in the Indian Ocean during 23 November to 17 December for station- 
Table 1. Nominal accuracies of the radiosondes according to the manufacturer.

\begin{tabular}{|c|c|c|c|}
\hline & & RS41-SGP & RS92-SGPD \\
\hline \multicolumn{2}{|l|}{ Weight } & $113 \mathrm{~g}$ & $280 \mathrm{~g}$ \\
\hline \multirow[t]{3}{*}{$\begin{array}{l}\text { Combined uncertainty in sounding } \\
(2 \sigma \text { confidence level }(95.5 \%)\end{array}$} & Temperature & $\begin{array}{l}0.3^{\circ} \mathrm{C}<16 \mathrm{~km} \\
0.4^{\circ} \mathrm{C}>16 \mathrm{~km}\end{array}$ & $0.5^{\circ} \mathrm{C}$ \\
\hline & Relative humidity & $4 \% \mathrm{RH}$ & $5 \% \mathrm{RH}$ \\
\hline & Pressure & \multicolumn{2}{|c|}{$\begin{array}{l}1.0>100 \mathrm{hPa} \\
0.6<100 \mathrm{hPa}\end{array}$} \\
\hline \multirow[t]{5}{*}{$\begin{array}{l}\text { Reproducibility in sounding } \\
\text { (standard deviation of differences } \\
\text { in twin soundings) }\end{array}$} & Temperature $^{\mathrm{a}}$ & $\begin{array}{l}0.15^{\circ} \mathrm{C}>100 \mathrm{hPa} \\
0.30^{\circ} \mathrm{C}<100 \mathrm{hPa}\end{array}$ & $\begin{array}{l}0.2^{\circ} \mathrm{C}>100 \mathrm{hPa} \\
0.3^{\circ} \mathrm{C} 100-20 \mathrm{hPa} \\
0.5^{\circ} \mathrm{C}<20 \mathrm{hPa}\end{array}$ \\
\hline & Relative humidity ${ }^{a}$ & \multicolumn{2}{|c|}{$2 \% \mathrm{RH}$} \\
\hline & Pressure & \multicolumn{2}{|c|}{$\begin{array}{l}0.5>100 \mathrm{hPa} \\
0.3<100 \mathrm{hPa}\end{array}$} \\
\hline & Wind speed & \multicolumn{2}{|c|}{$0.15 \mathrm{~m} \mathrm{~s}^{-1}$} \\
\hline & Wind direction ${ }^{b}$ & \multicolumn{2}{|c|}{$2^{\circ}$} \\
\hline
\end{tabular}

${ }^{\mathrm{a}}$ Ascent rate above $3 \mathrm{~m} \mathrm{~s}^{-1}$. ${ }^{\mathrm{b}}$ Wind speed above $3 \mathrm{~m} \mathrm{~s}^{-1}$.

ary observations, including 16 twin-radiosonde flights (JAMSTEC and BPPT, 2015). We also conducted intercomparison observations twice in the western Pacific on the way from Japan to the site off Sumatra (Fig. 1b and Table 2).

\subsection{Methods}

We used radiosonde models RS92-SGPD and RS41-SGP in this study. Their nominal accuracies are summarized in Table 1. Whereas the RS41-SG radiosonde used in the previous studies (Motl, 2014; Jauhiainen et al., 2014; Jensen et al., 2016) derived pressure from Global Positioning System (GPS) data with no pressure sensor, the RS41-SGP has a pressure sensor consisting of a silicon capacitor. The pressure and height data analyzed in this study were measured directly and derived from the hypsometric equation, respectively. Note that GPS-derived pressure and height were not used, unlike in the previous studies. Two different DigiCORA systems were used on R/V Mirai for the simultaneous RS92 and RS41 soundings. The receiving system (MW41) used for the RS41 included a processor (SPS331); processing and recording software (MW41 v2.2.1); GPS antenna (GA20); and ultra-high-frequency (UHF) antenna (RB21), which was part of the ASAP sounding station permanently installed on R/V Mirai. The RS41 sensors were calibrated with a new calibrator (RI41) and a barometer (PTB330). In contrast, we used a previous-generation system for the RS92: the receiving system (MW31) included a processor (SPS311), software (DigiCORA v3.64), GPS antenna (GA31), and UHF antenna (RM32). The instrumentation was temporarily placed in or on the aft wheelhouse. The RS92 sensors were calibrated with a calibrator (GC25) and a PTB330 barometer. Because version 3.61 of DigiCORA was incorrectly used during the cruises, all RS92 sounding data were simulated with DigiCORA v3.64 after the cruises.

The RS41 and RS92 radiosondes were directly attached to each other with sticky tape (Fig. 2), instead of hanging them from the two ends of a rod (Jensen et al., 2016), to facilitate the launching operations on the rocking ship deck. The two radiosondes were hung from a single $350 \mathrm{~g}$ Totex balloon with the cord of the RS41 radiosonde. The ascent rates were approximately 5 and $4 \mathrm{~m} \mathrm{~s}^{-1}$ during the MR15-03 and MR15-04 cruises, respectively (Table 2). Whereas nighttime twin-radiosonde flights could be carried out only once during the MR15-03 cruise owing to operations associated with oceanographic observations, we performed eight nighttime flights during the MR15-04 cruise (Fig. 1c and Table 2). In addition information about surface meteorological state, Table 2 lists convective available potential energy (CAPE), convective inhibition (CIN), and precipitable water (PW) calculated from RS41 data. CAPE and CIN were calculated for an air parcel corresponding to an average over the lowest $50 \mathrm{hPa}$.

A number of issues were addressed in post-processing the sounding data. During flight no. 33 (02:50 UTC on 16 December), the radiosondes oscillated vertically about the $0{ }^{\circ} \mathrm{C}$ level likely due to icing on the balloon, and hence only the data before the up-and-down motion were analyzed in this study. In the case of flight no. 9 (05:30 UTC on 16 September), we delayed the measurement time of the RS41 by $17 \mathrm{~s}$ in the analysis because the twin radiosondes flew horizontally just after launching, and the automatic determinations of the starting times disagreed between the RS92 and RS41. Be- 


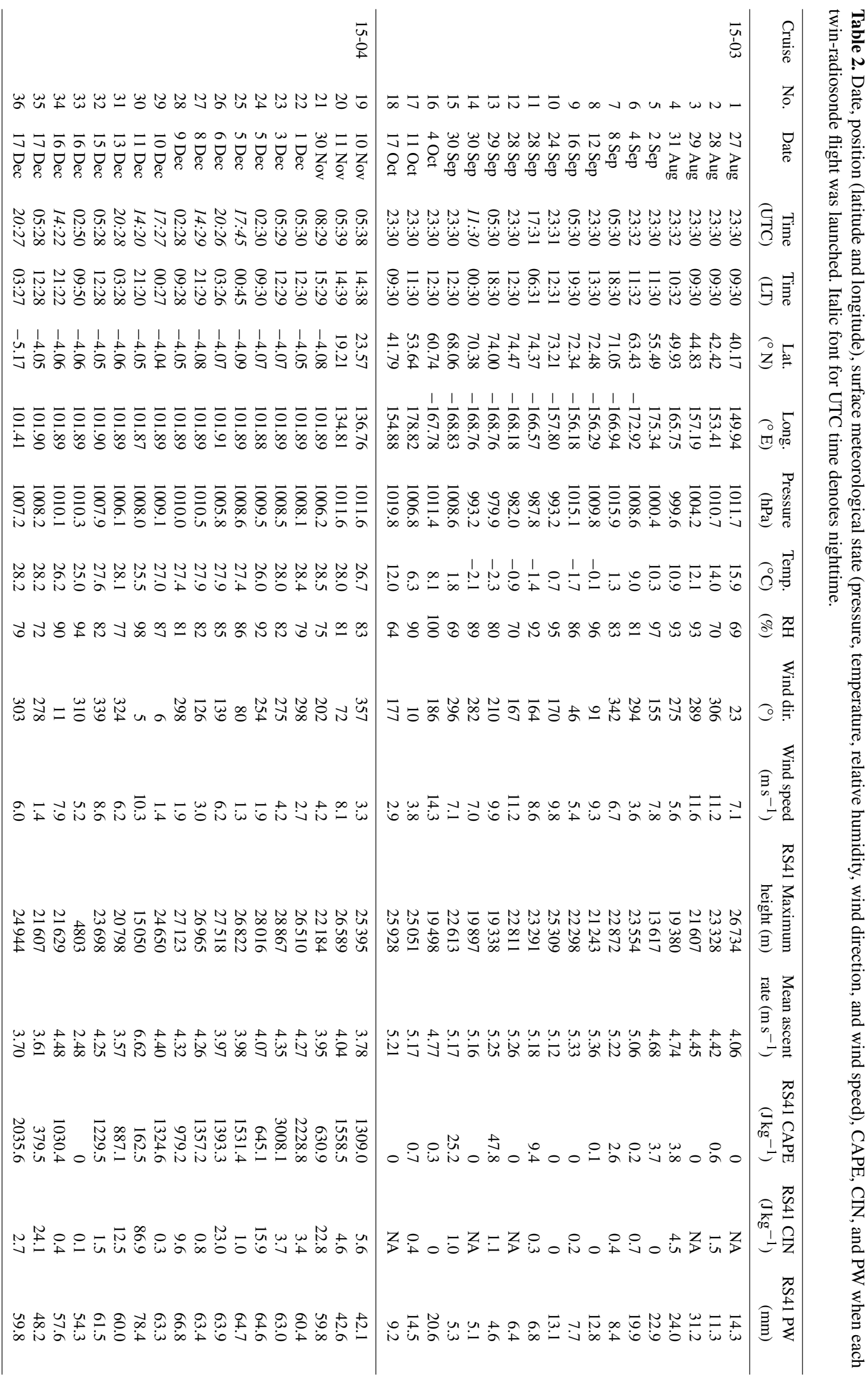



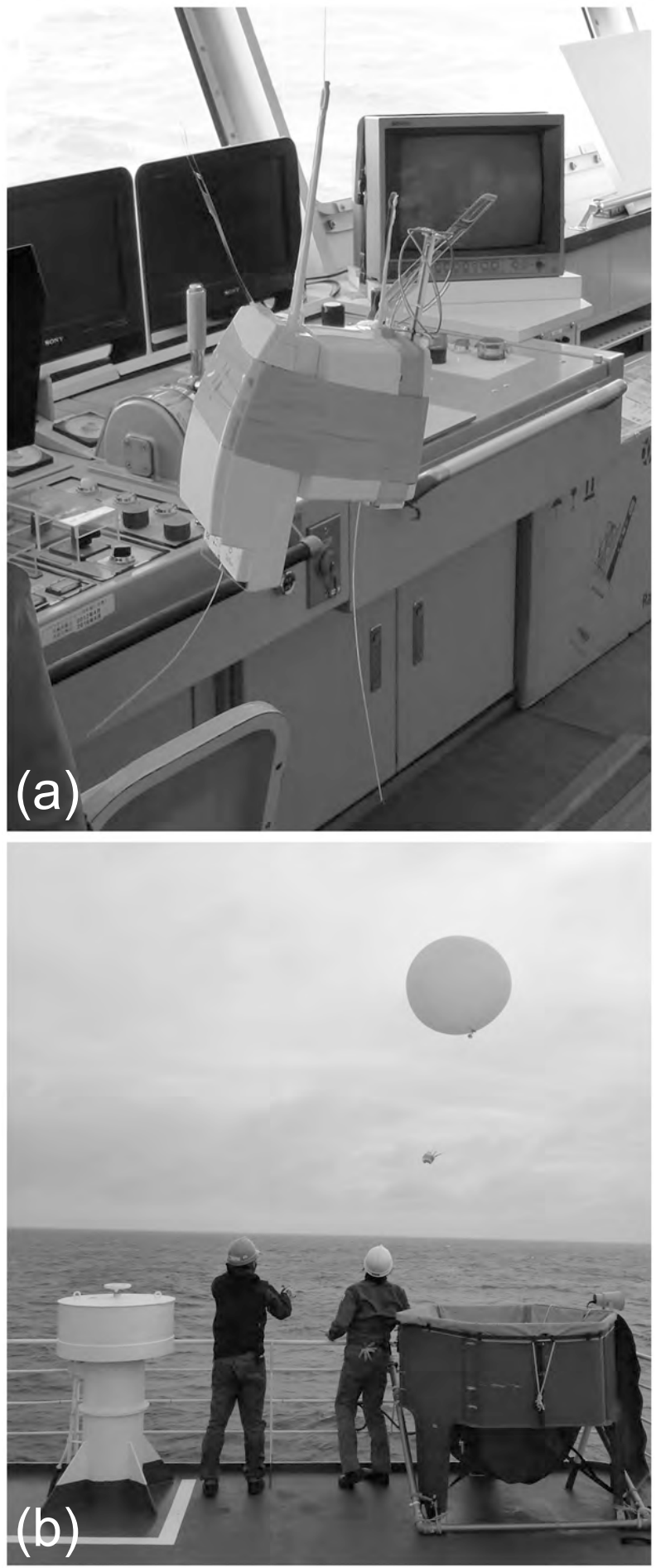

Figure 2. Photographs of (a) the RS92 and RS41 radiosondes directly attached to each other and (b) a launch on R/V Mirai.

cause the pressure values measured with the PTB330 barometer for the calibration of the RS92 had a bias of $0.18 \mathrm{hPa}$ before the launch of the no. 5 radiosondes, we subtracted $0.18 \mathrm{hPa}$ from the observed pressure values of the RS92 no. 1-4 radiosondes when the data were analyzed. The balloon release detection mode was changed from automatic to manual during the MR15-04 cruise, and the starting times of the RS92 and RS41 radiosondes during the MR15-04 cruise generally appeared to differ slightly. Therefore, the measurement times of all the RS92 radiosonde data during the MR1504 cruise were delayed by $1.7 \mathrm{~s}$ in the analysis.

\section{Results}

To facilitate comparison with the results of Jensen et al. (2016), we interpolated the RS92 radiosonde profiles to the same time step as the RS41 profiles and calculated differences between them at each $10 \mathrm{~m}$ vertical grid based on the RS41 radiosonde heights (Fig. 3). The vertical axis of Fig. 3 is therefore nearly equivalent to the passage of time. The biases, standard deviations, and root mean square (rms) differences were all smaller than the combined uncertainties, except that the rms differences of pressure above 100 exceeded $0.6 \mathrm{hPa}$ (Table 3). For temperature and wind speeds, the biases and rms differences in our experiments were nearly the same as those of Jensen et al. (2016), but the differences of pressure and relative humidity (RH) were much larger in our study.

\subsection{Pressure}

The pressure difference between the RS41 and RS92 radiosondes increased as the radiosondes rose to an altitude of about $5 \mathrm{~km}$ but averaged an almost constant $0.5-0.6 \mathrm{hPa}$ above that altitude (Fig. 3a). The 90th-percentile line revealed that the sensor-measured RS41 pressure was lower than the RS92 for more than $90 \%$ of the measurements above $5 \mathrm{~km}$. The percentage of the pressure differences that exceeded the combined uncertainty (Table 1) was $13.7 \%$ below $100 \mathrm{hPa}$ but $50.9 \%$ above $100 \mathrm{hPa}$. The bias of pressure causes the bias of geopotential height (Fig. 3b). The height difference increased with the altitude: The median of the RS41 height was greater than that of the RS92 by approximately $35 \mathrm{~m}$ at an altitude of $15 \mathrm{~km}$, and $100 \mathrm{~m}$ at $22 \mathrm{~km}$.

We also checked the GPS-derived pressure of the RS41 radiosondes. Figure 4 shows the difference between the RS92 pressure and the RS41 GPS-derived one. The use of the GPSderived pressure reduced the bias by approximately $0.2 \mathrm{hPa}$ above an altitude of $15 \mathrm{~km}$, but there was still a bias of $0.4 \mathrm{hPa}$ or more at most altitudes. The median of the difference in Fig. 4 was almost the same as in Fig. 3a around an altitude of $5 \mathrm{~km}$. The use of the GPS did not essentially improve the pressure bias. This is different from the results of Jensen et al. (2016).

\subsection{Relative humidity}

The median of the relative humidity differences peaked at approximately $2 \% \mathrm{RH}$ near $10 \mathrm{~km}$ (Fig. 3c), a result consistent 

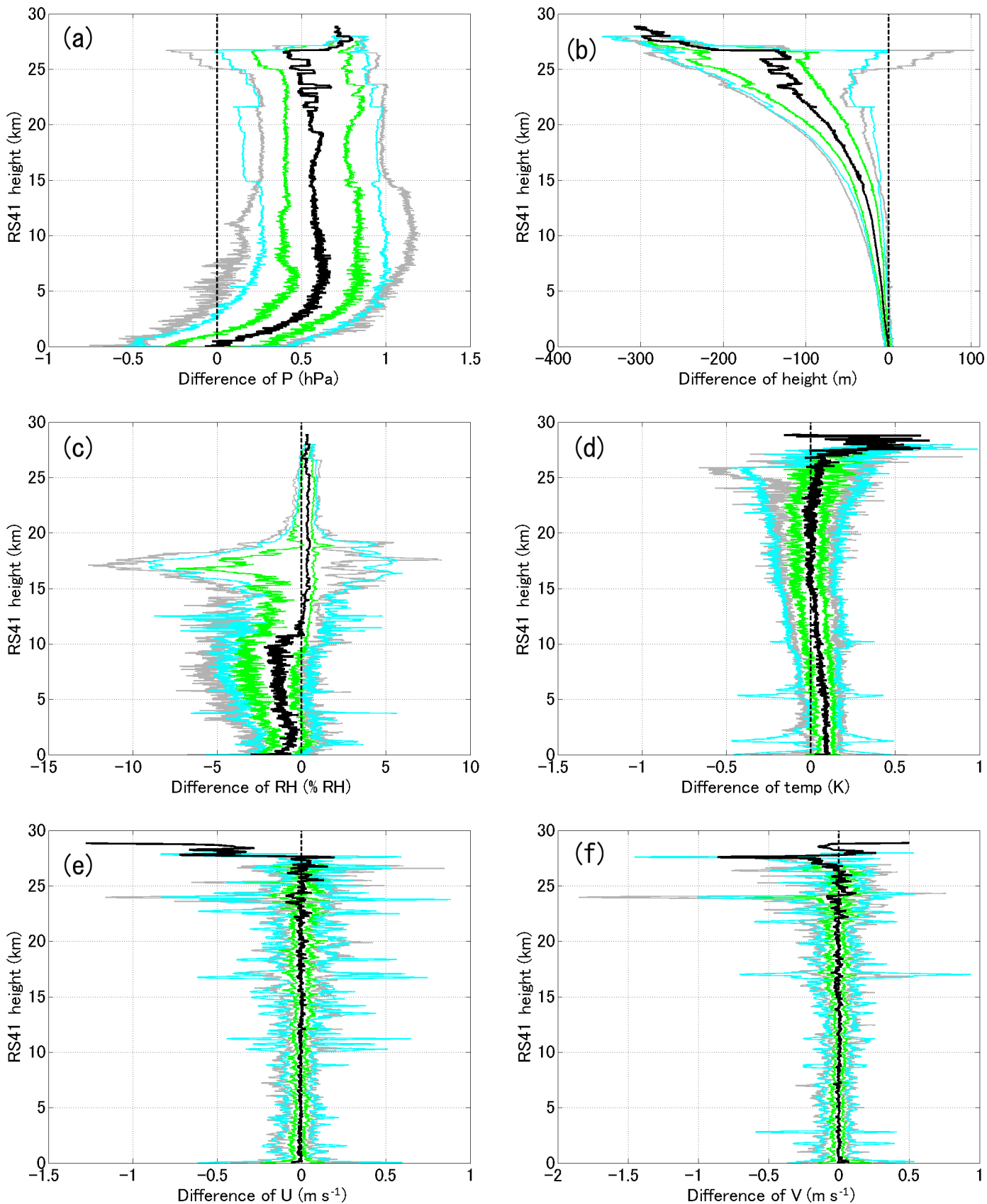

Figure 3. Vertical profiles of the median (black), 25-75th percentile (green), 10-90th percentile (gray), and mean \pm standard deviation (cyan) of all differences between the RS92 and RS41 observations (RS92-RS41) for (a) pressure, (b) geopotential height, (c) relative humidity, (d) temperature, (e) zonal wind, and (f) meridional wind.

with the data of Jensen et al. (2016). The humidity difference was also large near the sea surface in our analysis. For $13.0 \%$ of the measurements, the absolute value of the difference exceeded $4.0 \% \mathrm{RH}$, which is the combined uncertainty of the RS41-SGP. One noteworthy feature of Fig. 3c is that there were quite large differences of relative humidity at a height of about $17 \mathrm{~km}$, although the median difference was less than $0.5 \%$ RH. Figure 5 shows the relationship between the humidity difference and temperature for each category of relative humidity. During both the MR15-03 and MR15-04 cruises, the RS41 radiosonde recorded a higher mean relative humidity than the RS92 for all humidity ranges. The humidity difference peaked at around $-40^{\circ} \mathrm{C}$, a pattern similar to Fig. 17 of Jensen et al. (2016). The differences were relatively small, in the range of -50 to $-70^{\circ} \mathrm{C}$, but the RS41 humidity was much higher than the RS92 at temperatures be- 
Table 3. Biases, rms differences, and standard deviations (SDs) of the variables between the RS92 and RS41 radiosondes. The bias is the mean of RS92-RS41 differences.

\begin{tabular}{|c|c|c|c|c|c|c|}
\hline \multirow[t]{2}{*}{ Variable } & \multicolumn{2}{|c|}{ Total } & \multicolumn{2}{|c|}{$\begin{array}{c}\text { MR15-03 } \\
\text { (Subarctic-Arctic) }\end{array}$} & \multicolumn{2}{|c|}{$\begin{array}{c}\text { MR15-04 } \\
\text { (Subtropics-tropics) }\end{array}$} \\
\hline & Bias & $\begin{array}{r}\mathrm{rms} \\
\mathrm{SD}\end{array}$ & Bias & $\begin{array}{r}\mathrm{rms} \\
\mathrm{SD}\end{array}$ & Bias & $\begin{array}{r}\mathrm{rms} \\
\mathrm{SD}\end{array}$ \\
\hline $\begin{array}{l}\text { Temperature }\left({ }^{\circ} \mathrm{C}\right) \\
P_{\mathrm{RS} 92}>100 \mathrm{hPa}\end{array}$ & +0.04 & $\begin{array}{l}0.17 \\
0.17\end{array}$ & +0.01 & $\begin{array}{l}0.15 \\
0.15\end{array}$ & +0.06 & $\begin{array}{l}0.19 \\
0.18\end{array}$ \\
\hline $\begin{array}{l}\text { Temperature }\left({ }^{\circ} \mathrm{C}\right) \\
P_{\mathrm{RS} 92}<100 \mathrm{hPa}\end{array}$ & -0.01 & $\begin{array}{l}0.22 \\
0.22\end{array}$ & -0.10 & $\begin{array}{l}0.27 \\
0.25\end{array}$ & +0.05 & $\begin{array}{l}0.18 \\
0.17\end{array}$ \\
\hline $\begin{array}{l}\text { Pressure }(\mathrm{hPa}) \\
P_{\mathrm{RS} 92}>100 \mathrm{hPa}\end{array}$ & +0.52 & $\begin{array}{l}0.67 \\
0.42\end{array}$ & +0.41 & $\begin{array}{l}0.58 \\
0.40\end{array}$ & +0.64 & $\begin{array}{l}0.76 \\
0.41\end{array}$ \\
\hline $\begin{array}{l}\text { Pressure }(\mathrm{hPa}) \\
P_{\mathrm{RS} 92}<100 \mathrm{hPa}\end{array}$ & +0.55 & $\begin{array}{l}0.67 \\
0.38\end{array}$ & +0.57 & $\begin{array}{l}0.61 \\
0.21\end{array}$ & +0.53 & $\begin{array}{l}0.71 \\
0.47\end{array}$ \\
\hline $\begin{array}{l}\text { Relative humidity } \\
(\% \mathrm{RH})\end{array}$ & -0.89 & $\begin{array}{l}3.14 \\
3.01\end{array}$ & -0.50 & $\begin{array}{l}2.14 \\
2.08\end{array}$ & -1.26 & $\begin{array}{l}3.86 \\
3.64\end{array}$ \\
\hline $\begin{array}{l}\text { Zonal wind speed } \\
\left(\mathrm{m} \mathrm{s}^{-1}\right)\end{array}$ & -0.0017 & $\begin{array}{l}0.18 \\
0.18\end{array}$ & +0.0027 & $\begin{array}{l}0.17 \\
0.17\end{array}$ & -0.0059 & $\begin{array}{l}0.18 \\
0.18\end{array}$ \\
\hline $\begin{array}{l}\text { Meridional wind speed } \\
\left(\mathrm{m} \mathrm{s}^{-1}\right)\end{array}$ & -0.0051 & $\begin{array}{l}0.17 \\
0.17\end{array}$ & +0.0104 & $\begin{array}{l}0.18 \\
0.18\end{array}$ & -0.0199 & $\begin{array}{l}0.16 \\
0.15\end{array}$ \\
\hline
\end{tabular}

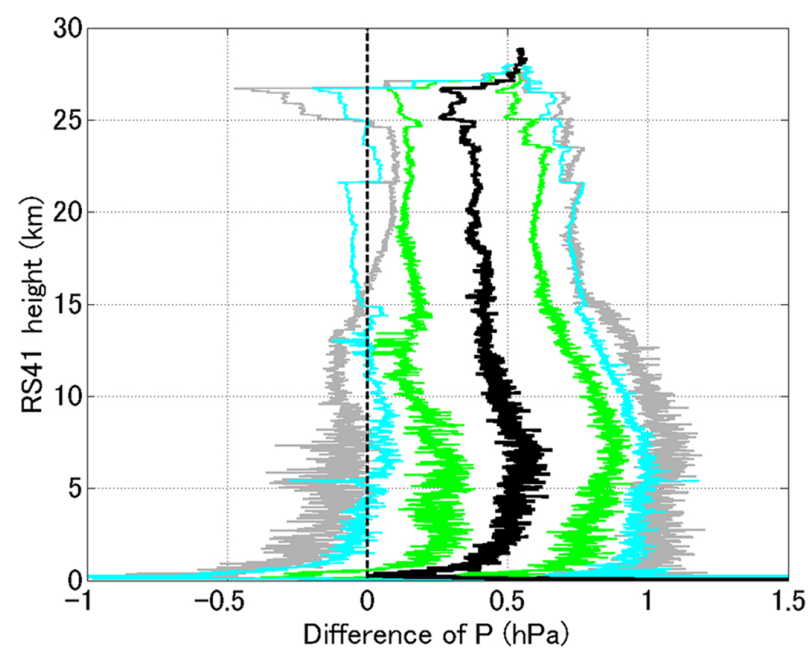

Figure 4. As in Fig. 3a but for between the RS41 GPS-derived and RS92 pressures (RS92-RS41).

low $-80^{\circ} \mathrm{C}$ (Fig. 5b). The atmosphere associated with temperatures below $-80^{\circ} \mathrm{C}$ corresponds to the tropopause in the tropics, where the greatest differences were apparent at altitudes of about $17 \mathrm{~km}$ (Fig. 3c).

\subsection{Temperature}

In the case of temperature, although there was a slight positive bias below an altitude of $10 \mathrm{~km}$, the median of the dif- ferences was within $\pm 0.12^{\circ} \mathrm{C}$ below an altitude of $26 \mathrm{~km}$ (Fig. 3d). The median exceeded $0.5^{\circ} \mathrm{C}$ above $27 \mathrm{~km}$, but only four flights reached that height, and the large median was attributable to differences on two of the flights (nos. 23 and 24). The percentages of the temperature difference that exceeded the combined uncertainty were $4.0 \%$ below $16 \mathrm{~km}$ and $5.9 \%$ above $16 \mathrm{~km}$. Figure $3 \mathrm{~d}$ also shows that the standard deviation of the temperature differences was smaller at altitudes below $16 \mathrm{~km}$, but there were quite large standard deviations near the surface and at altitudes of about 1.3 and $5.3 \mathrm{~km}$ because of some outliers. The extreme temperature difference, which reached $2.75^{\circ} \mathrm{C}$ at an altitude of $1.27 \mathrm{~km}$, was observed on 10 December in the tropics (Fig. 6a). The RS92 temperature became much lower than the RS41 just after the radiosondes passed through a saturated layer into a dry layer. The greater reduction of the RS92 temperature was probably due to the "wet-bulbing" effect mentioned by Jensen et al. (2016), who indicated that the sequential pulse heating method with relatively long non-heating periods may not be sufficient to eliminate icing/wetting of the RS92 sensor. A large temperature difference that was likely caused by the wet-bulbing effect was also observed in a sounding in the Arctic, although the maximum difference was less than $0.75^{\circ} \mathrm{C}$ (Fig. 6b).

Figure 7 shows the cases of extreme temperature differences that contributed to the greater standard deviation and cannot be explained by the wet-bulbing effect. For the flight on 11 December (Fig. 7a), there was a large temperature discrepancy inside the saturated layer. In that case, the radioson- 

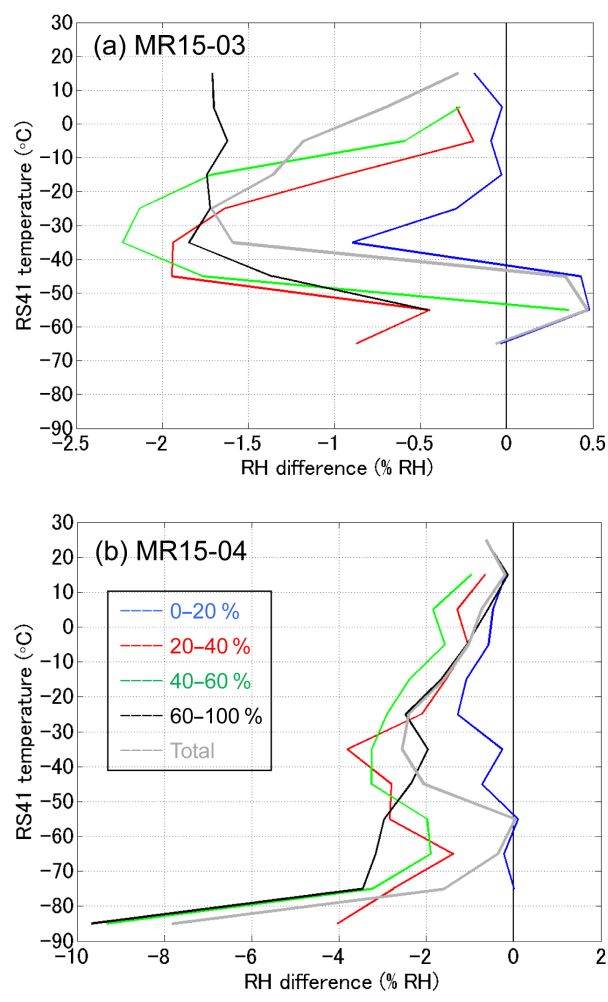

Figure 5. Mean difference in relative humidity between the RS92 and RS41 radiosondes (RS92-RS41) as a function of the RS41 temperature for relative humidity ranges of 0-20\% (blue), 20-40\% (red), 40-60\% (green), 60-100\% (black), and 0$100 \%$ (gray). (a) MR15-03 and (b) MR15-04.

des were launched in heavy rain, and the ascent rate dropped to nearly zero at approximately $5.4 \mathrm{~km}$, probably because of rain or snow and freezing of the balloon. Furthermore, the horizontal wind speed was less than $3.0 \mathrm{~m} \mathrm{~s}^{-1}$ around this altitude. As a result, the temperature sensors were presumably not ventilated sufficiently. In the case of the flights on 1 and 3 December (Fig. $7 b$ and c), the RS41 temperatures were higher than the RS92 by more than $1.0^{\circ} \mathrm{C}$ near the surface. Because the surface reference air temperatures were close to the RS92 temperatures at the lowest level, we suspect that the RS41 temperatures were too high. These large temperature differences led to enormous discrepancies in CAPE: $864.6 \mathrm{~J} \mathrm{~kg}^{-1}$ for no. 22 and $1819.0 \mathrm{~J} \mathrm{~kg}^{-1}$ for no. 23 . Yoneyama et al. (2002) have indicated that ship body heating can affect radiosonde sensors. However, that effect was restricted to within several tens of meters of the sea surface in their experiments. Although we cannot completely exclude the possibility that the temperature sensors of the two RS41 radiosondes were improperly heated by the body of the ship or direct insolation or improper handling near the surface, the reason for these large discrepancies remains unclear.
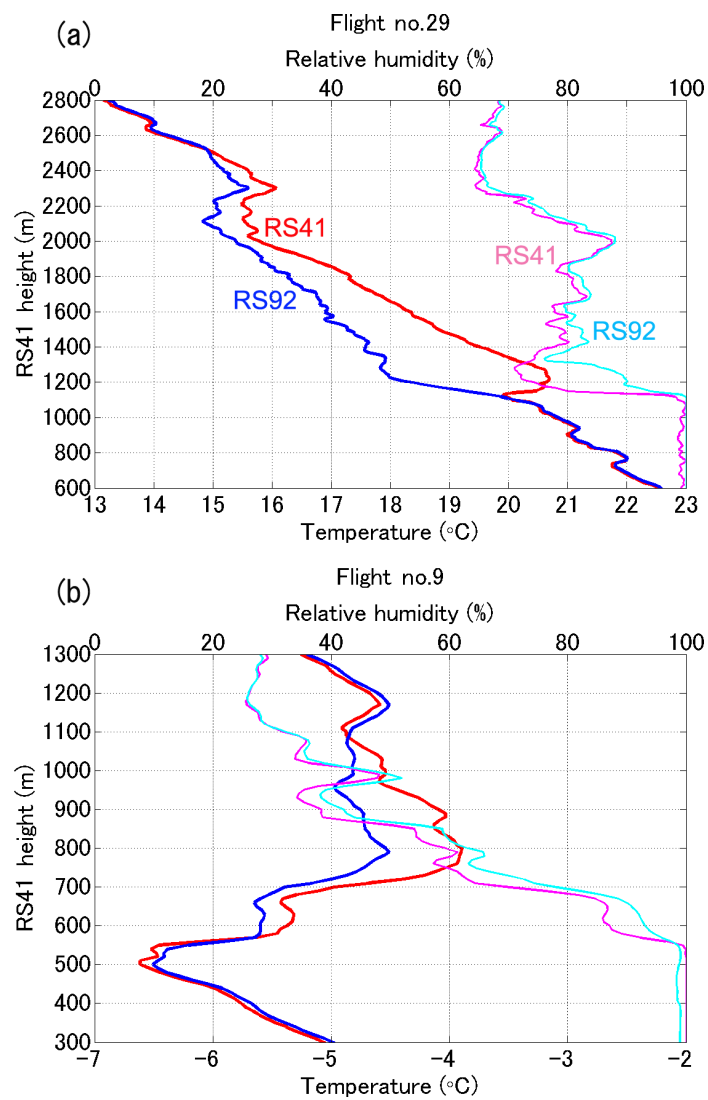

Figure 6. Vertical profiles of the RS41 temperature (red), RS92 temperature (blue), RS41 relative humidity (magenta), and RS92 relative humidity (cyan). (a) Flight no. 29 launched at 17:27 UTC on 10 December 2015 in the tropics, and (b) flight no. 9 launched at 05:30 UTC on 16 September 2015 in the Arctic.

\subsection{Wind speed}

Vertical profiles of the wind speed differences are shown in Fig. $3 e$ and $\mathrm{f}$. The percentages of the differences in the zonal and meridional wind speeds that exceeded $0.5 \mathrm{~m} \mathrm{~s}^{-1}$ were 1.9 and $1.5 \%$, respectively. Although both the zonal and meridional wind speeds agreed to within $0.5 \mathrm{~m} \mathrm{~s}^{-1}$ for almost all measurements, several spikes can be seen in the standard deviations and percentiles. In half of all flights, the magnitude of the difference of the horizontal wind speed exceeded $1.0 \mathrm{~m} \mathrm{~s}^{-1}$ for a brief moment. The wind speed data in our soundings were noisier than those reported by Jensen et al. (2016).

\section{Discussion}

\subsection{Day-night differences}

Figure 8 compares the differences between daytime (10 flights) and nighttime (8 flights) for the soundings during the MR15-04 cruise. The median of the pressure differ- 

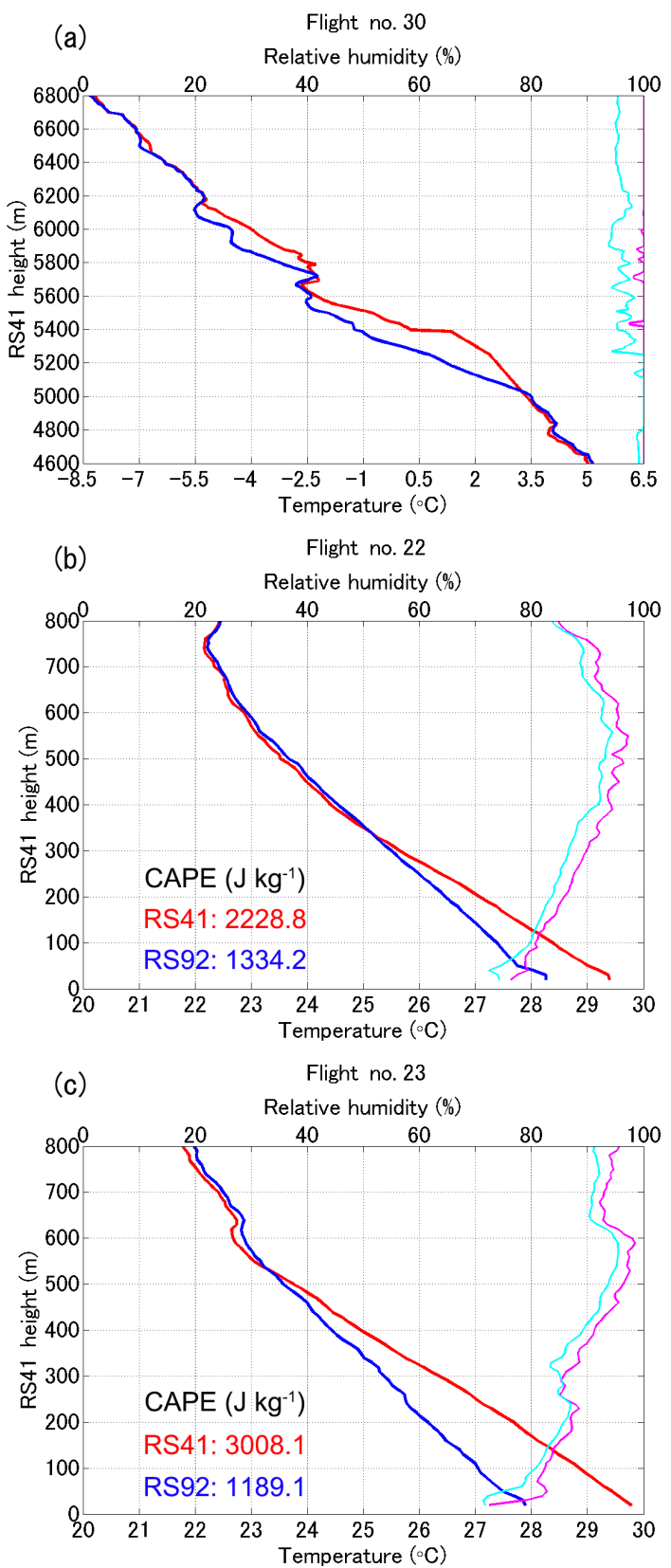

Figure 7. As Fig. 6 but for (a) flight no. 30 launched at 14:20 UTC on 11 December 2015, (b) flight no. 22 launched at 05:30 UTC on 1 December 2015, and (c) flight no. 23 launched at 05:29 UTC on 3 December 2015. All launches in the tropics.

ence was greater in the day than at night above an altitude of $4.5 \mathrm{~km}$ (Fig. 8a). The median of the nighttime differences was close to that of the daytime flights in the Arctic cruise below an altitude of $15 \mathrm{~km}$, the implication being that the day-night difference might reflect some effect of solar heating.

The median profiles of temperature differences in the day and night were close to each other, with slightly larger differences in the night at altitudes of 5-15 km (Fig. 8b). The day- time difference became greater above approximately $24 \mathrm{~km}$, a pattern similar to the results of Jensen et al. (2016). According to them, the difference in the radiation correction schemes between the RS92 and RS41 may be the dominant cause of these temperature differences, particularly at high solar elevation angles and low pressures.

The median of the relative humidity difference was larger during the day than at night from the surface to an altitude of $20 \mathrm{~km}$ and was especially large at an altitude of about $17 \mathrm{~km}$ (Fig. 8c). The very large difference (RS41 > RS92) in relative humidity around the tropopause shown in Figs. $3 \mathrm{c}$ and $5 \mathrm{~b}$ occurred in the daytime. This pattern is consistent with the results of Jauhiainen et al. (2014), who indicated that the difference was largely due to the dissimilar approaches used to compensate for the heating effect of solar radiation on the humidity sensor. Similar dry biases were reported for the RS92 radiosonde with the earlier version of DigiCORA (Vömel et al., 2007; Yoneyama et al., 2008), although the dry bias was generally absent from later observations (Ciesielski et al., 2014; Yu et al., 2015) because the bias due to solar heating was removed by a correction scheme included in the v3.64 software or developed by Wang et al. (2013). Figure 9 shows the relative difference of relative humidity in the daytime between the RS92 and RS41 radiosondes. The relative difference is defined to be the relative humidity difference expressed as a percentage of the RS41 relative humidity. The relative difference was small in the lower troposphere and became greater as the radiosondes rose higher. Its median peaked at $-36.9 \%$ at an approximate altitude of $19 \mathrm{~km}$. This pattern of the vertical profile of relative difference is similar to that between the RS92 radiosonde and a reference instrument shown by Vömel et al. (2007), but the values in Fig. 9 are less than half of those in Fig. 6 of Vömel et al. (2007) because the RS92 DigiCORA v3.64 and RS41 relative humidity data are already inherently better.

We evaluated how the differences between the two types of radiosonde affected CAPE, CIN, and PW (Table 4). CAPE tended to be larger when the RS92 was used in the nighttime. This was due to slightly higher temperature of RS92 near the surface (Fig. 8b). On the other hand, in the daytime the RS41 CAPE was larger than the RS92 and the RS41 CIN was smaller than the RS92. The day-night differences in the CAPE and CIN biases were caused by the difference in the humidity bias between daytime and nighttime. The near-surface humidity of the RS41 was larger than that of the RS92 in the daytime (Fig. 8c). The larger pressure bias in daytime (Fig. 8a), which means an atmospheric layer in the RS41 observation, also may contribute to the daytime bias of CAPE. Although the bias of PW was less than $1.0 \mathrm{~mm}$, the daytime humidity difference between the RS41 and RS92 affected PW. The ratio of the RS41 to the RS92 PW was dependent on solar altitude angle (Fig. 10), similar to the general shape of the dependence indicated by Miloshevich et al. (2009) (their Fig. 4a), suggesting that the humidity bias was mainly related to solar heating. 

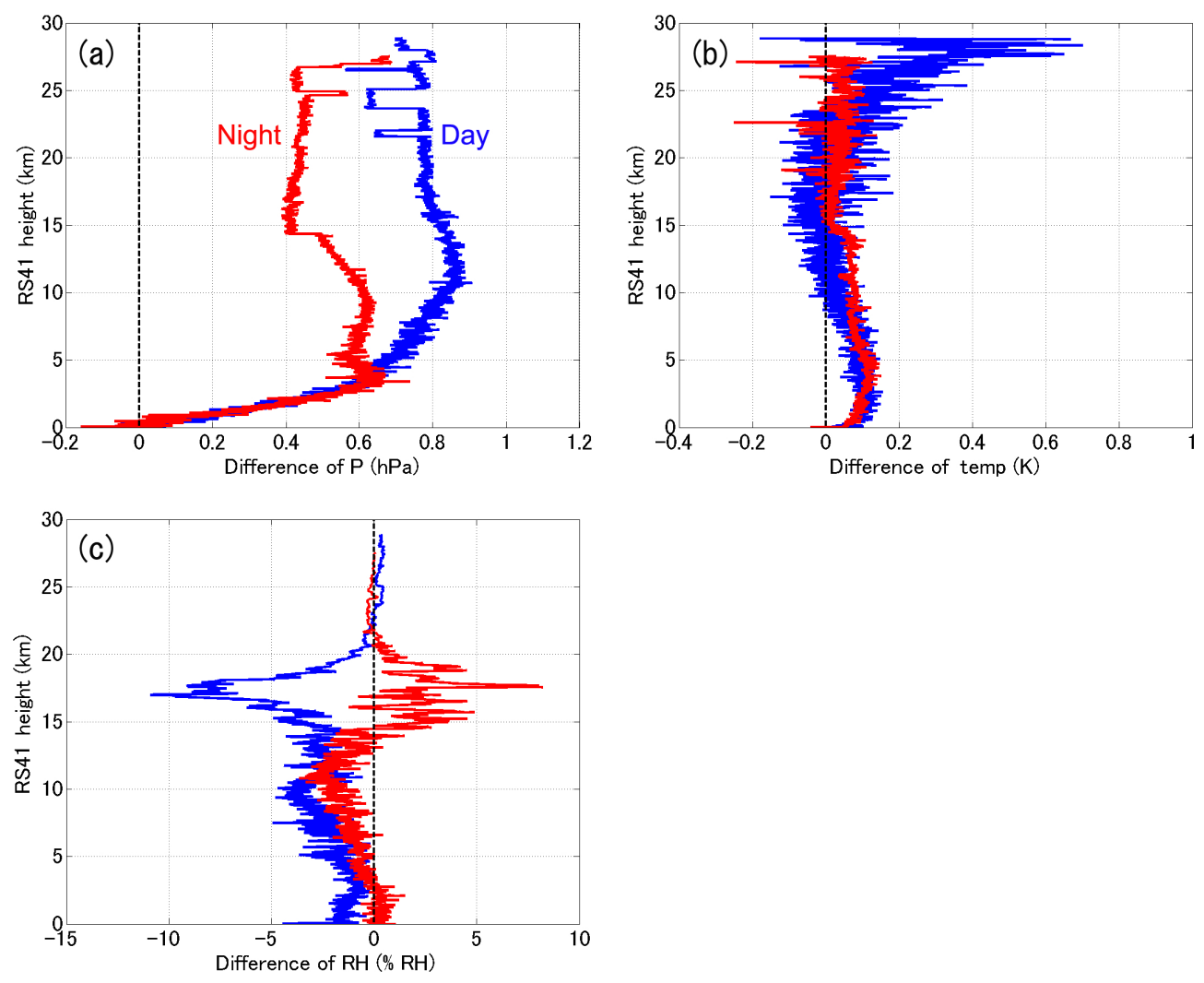

Figure 8. Differences between the RS92 and RS41 radiosonde (RS92-RS41) results for daytime (blue) and nighttime (red) flights during the MR15-04 cruise for (a) pressure, (b) temperature, and (c) relative humidity.

\subsection{Humidity correction}

Figures $8 \mathrm{c}, 9$, and 10 imply that a small dry bias still remains in the RS92 radiosonde observations. We attempted to correct the RS92 relative humidity obtained during the MR1504 cruise by using the RS41 as a reference instrument. However, this is not based on an assertion that the RS42 measurements must be true values. There is no independent evidence to judge which radiosonde was more accurate. The RS41 relative humidity was larger than the RS92 at an altitude between 3 and $13 \mathrm{~km}$ (Fig. 8c), suggesting that the RS41 humidity also has a slight moist bias that is unrelated to the radiation correction scheme. The correction attempted in this subsection is a proposal to bridge the gap in relative humidity between the RS41 and RS92 radiosondes.

We used the cumulative distribution function (CDF) matching method proposed by Nuret et al. (2008) and Ciesielski et al. (2009) to make the correction. The details of this method can be found in Ciesielski et al. (2009). We first created CDFs of relative humidity for the RS92 and RS41 using temperature bins of 20 between +30 and $-90^{\circ} \mathrm{C}(10$ to $30,-10$ to $10,-30$ to $-10,-50$ to $-30,-70$ to -50 , and -90 to $-70^{\circ} \mathrm{C}$ ) using $5 \mathrm{hPa}$ radiosonde data in $5 \% \mathrm{RH}$ intervals. Figure 11 shows the CDFs of the RS92 and RS41 in the temperature range -90 to $-70^{\circ} \mathrm{C}$ as an example. The fre- quency of lower relative humidity was greater for the RS92 in this temperature range, which includes the tropopause (Fig. 11a). We then, for example, paired the RS92 value of $27.50 \% \mathrm{RH}$ at the 71.23th percentile with the corresponding RS41 value at this same percentile. The RS41 relative humidity at the 71.23 th percentile was $36.43 \% \mathrm{RH}$, and the difference between 36.43 and $27.50 \% \mathrm{RH}(=+8.93 \% \mathrm{RH})$ was the bias correction for the RS92 value of $27.5 \% \mathrm{RH}$. Figure $11 \mathrm{~b}$ shows the bias correction over the entire relative humidity range for temperatures of -90 to $-70^{\circ} \mathrm{C}$.

Table 5 shows the daytime bias correction for the entire range of temperatures and relative humidities. The correction was seldom more than $5 \% \mathrm{RH}$ when the RS92 temperature exceeded $-60^{\circ} \mathrm{C}$. The correction was large for RS92 radiosonde values in the range $15-50 \% \mathrm{RH}$ and temperatures of $-80^{\circ} \mathrm{C}$, with a maximum of $+8.93 \% \mathrm{RH}$. This pattern is similar to that of the correction table for the RS80 radiosonde in the daytime reported by Ciesielski et al. (2010) (their Fig. 7b), but the values in Table 5 are much smaller. We corrected the daytime RS92 relative humidity values obtained during the MR15-04 cruise using Table 5. The correction value for an arbitrary RS92 measurement can be obtained by linear two-dimensional interpolation using Table 5 and the RS92 temperature and relative humidity. Figure 12 shows median profiles of the differences between the RS92 and 
Table 4. Biases and standard deviations of CAPE, CIN, and PW between the RS92 and RS41 radiosondes. The bias is the mean of RS92RS41 differences. Values in parentheses are the statistics without the two outliers shown in Fig. 7b-c (flight nos. 22 and 23 ).

\begin{tabular}{lccc|rrr|rrr}
\hline & \multicolumn{2}{c}{ MR15-03 } & \multicolumn{2}{c|}{$\begin{array}{c}\text { MR15-04 } \\
\text { Daytime }\end{array}$} & \multicolumn{3}{c}{$\begin{array}{c}\text { MR15-04 } \\
\text { Nighttime }\end{array}$} \\
\cline { 2 - 9 } & RS41 mean & Bias & SD & RS41 mean & Bias & SD & RS41 mean & Bias & SD \\
\hline $\begin{array}{l}\text { CAPE } \\
\left(\mathrm{J} \mathrm{kg}^{-1}\right)\end{array}$ & 5.3 & -0.9 & 1.8 & $\begin{array}{r}1196.9 \\
(841.5)\end{array}$ & $\begin{array}{r}-331.7 \\
(-75.4)\end{array}$ & $\begin{array}{r}614.7 \\
(222.4)\end{array}$ & 1215.3 & 111.1 & 94.8 \\
\hline $\begin{array}{l}\mathrm{CIN} \\
\left(\mathrm{J} \mathrm{kg}^{-1}\right)\end{array}$ & 0.8 & 0.8 & 1.9 & $\begin{array}{r}9.2 \\
(10.6)\end{array}$ & $\begin{array}{r}1.1 \\
(1.0)\end{array}$ & $\begin{array}{r}4.4 \\
(5.0)\end{array}$ & 16.0 & -0.2 & 1.3 \\
\hline $\begin{array}{l}\mathrm{PW} \\
(\mathrm{mm})\end{array}$ & 13.2 & -0.2 & 0.3 & $\begin{array}{r}56.3 \\
(55.0)\end{array}$ & $\begin{array}{r}-0.9 \\
(-0.6)\end{array}$ & $\begin{array}{r}1.1 \\
(1.0)\end{array}$ & 63.9 & 0.1 & 0.5 \\
\hline
\end{tabular}

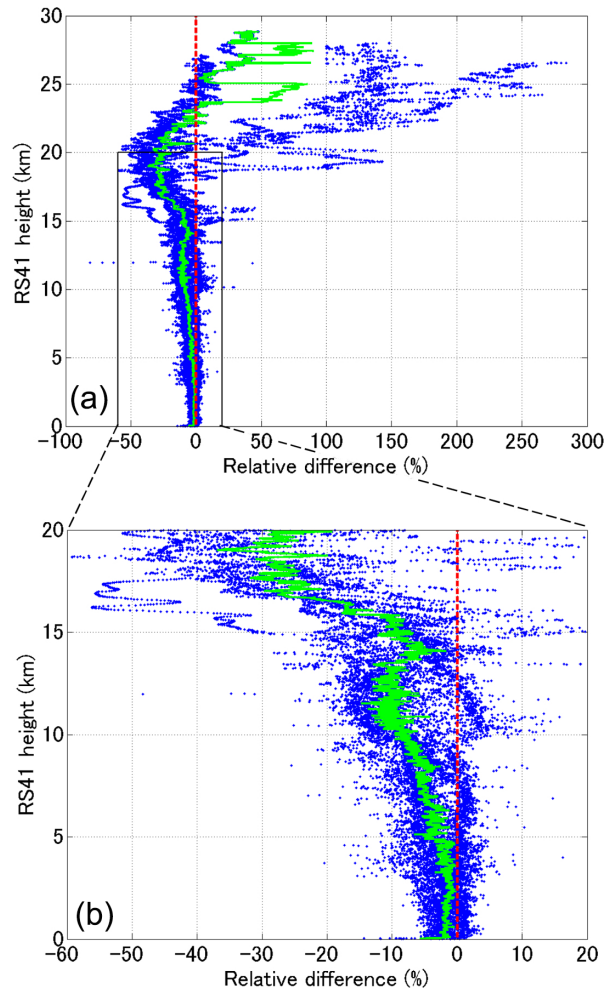

Figure 9. Relative difference between the RS92 and RS41 relative humidity obtained during the daytime on the MR15-04 cruise (blue dots, \%). Relative difference is defined as the relative humidity difference expressed as a percentage of the RS41 relative humidity. Green line denotes the median of the relative difference. (b) shows an enlargement of part (a).

RS41 radiosondes before and after the correction. Although the median of the magnitude of the differences still exceeded $2.0 \% \mathrm{RH}$ around 120,150 , and $560 \mathrm{hPa}$, most of the medians were within $\pm 1.0 \% \mathrm{RH}$. The mean of the relative humidity difference of the $5 \mathrm{hPa}$ interval data was $-2.02 \% \mathrm{RH}$ if no correction was made; this difference was reduced to $-0.01 \% \mathrm{RH}$ after the correction.

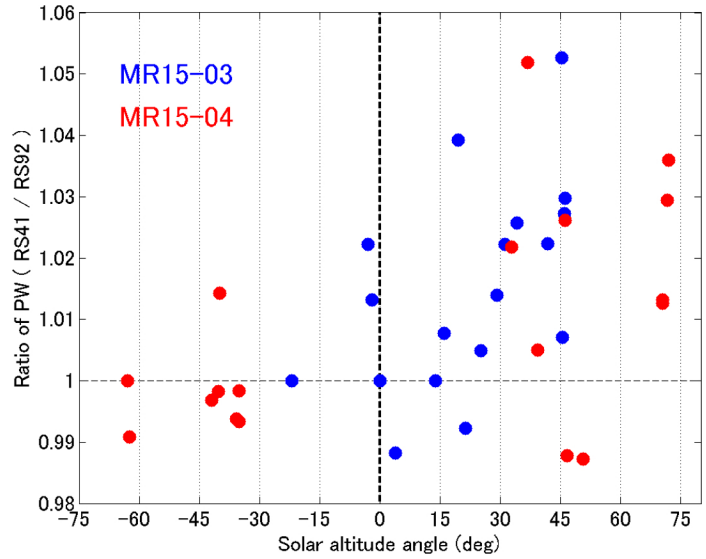

Figure 10. The ratio of the RS41 to the RS92 PW as a function of solar altitude angle. Blue and red dots represent soundings in the MR15-03 and MR15-04 cruises, respectively.

\section{Conclusions}

To examine differences between the RS41 and RS92 radiosondes, a total of 36 twin-radiosonde flights were performed over the Arctic Ocean, Bering Sea, western North Pacific Ocean, and the tropical Indian Ocean during two cruises of R/V Mirai in 2015. We used the model RS41-SGP radiosonde, which has a pressure sensor, unlike previous studies that used the RS41-SG, which has no pressure sensor.

The biases, standard deviations, and rms of the differences between the RS41 and RS92 over all flights and heights were smaller than the nominal combined uncertainties of the RS41, except that the rms differences of pressure above $100 \mathrm{hPa}$ exceeded $0.6 \mathrm{hPa}$. Whereas the biases and the rms differences of temperature and wind speeds were close to those reported by Jensen et al. (2016), the differences of pressure and relative humidity were greater in our experiments. The pressure difference increased as the radiosondes rose higher; the median and mean were $0.5-0.6 \mathrm{hPa}$ at altitudes above $5 \mathrm{~km}$. This pressure difference corresponded to 

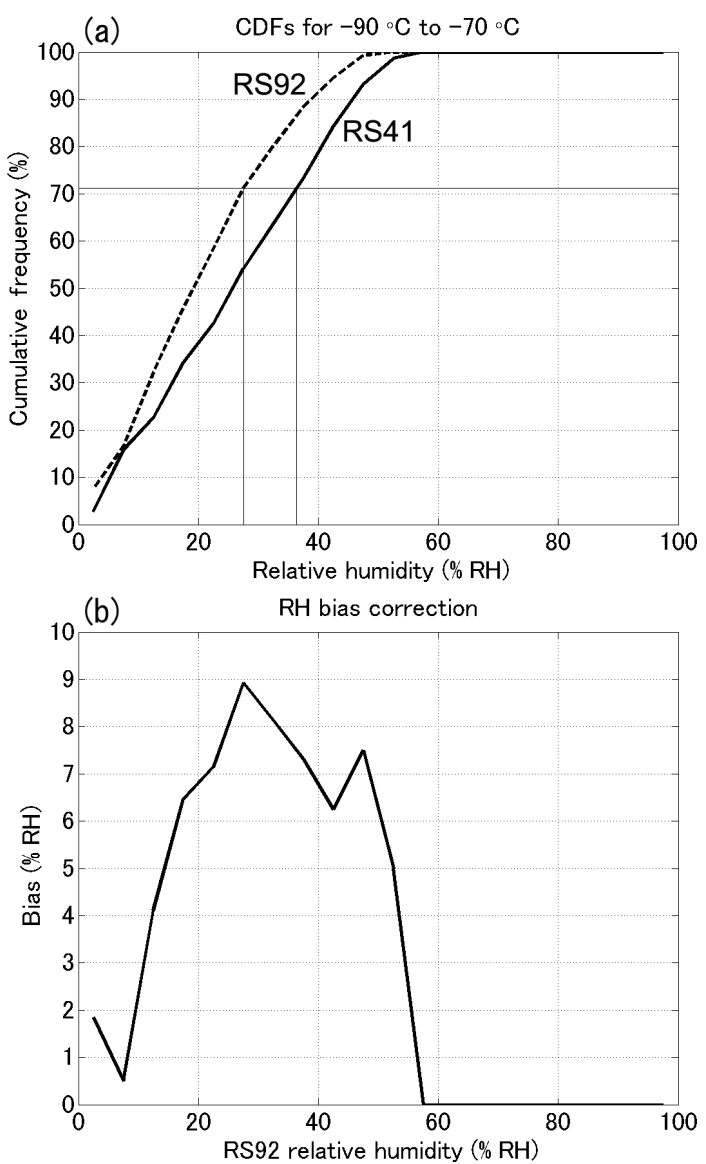

Figure 11. (a) CDFs of relative humidity for the RS92 (bold dashed line) and RS41 (bold solid line) data in the temperature range of -90 to $-70^{\circ} \mathrm{C}$. The daytime data obtained during the MR15-04 cruise were used. Thin solid lines illustrate the CDF matching technique (see text). (b) Bias correction of relative humidity for the same temperature range.

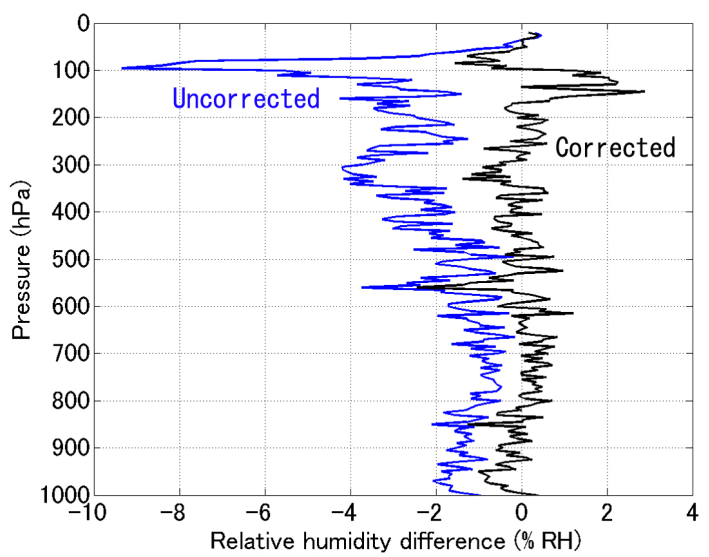

Figure 12. Medians of the relative humidity difference between the RS92 and RS41 radiosondes obtained during the daytime on the MR15-04 cruise. Blue and black lines show the profiles before and after the bias correction of the RS92 data.
Table 5. Bias correction table of relative humidity that was created by matching the CDFs from the RS92 data to the RS41 data (\% RH) based on the daytime data obtained during the MR15-04 cruise.

\begin{tabular}{|c|c|c|c|c|c|c|}
\hline & $\leq-80^{\circ} \mathrm{C}$ & $-60^{\circ} \mathrm{C}$ & $-40^{\circ} \mathrm{C}$ & $-20^{\circ} \mathrm{C}$ & $0^{\circ} \mathrm{C}$ & $\geq 20^{\circ} \mathrm{C}$ \\
\hline $2.5 \% \mathrm{RH}$ & 1.84 & 0 & -0.42 & 0 & 0 & 0 \\
\hline 7.5 & 0.50 & 2.35 & 0.50 & 0.25 & 0.36 & 0 \\
\hline 12.5 & 4.12 & 2.14 & 3.24 & 1.15 & 0.79 & 0 \\
\hline 17.5 & 6.47 & 3.13 & 2.31 & 1.43 & 1.00 & 0 \\
\hline 22.5 & 7.14 & 3.33 & 2.86 & 1.67 & 1.67 & 0 \\
\hline 27.5 & 8.93 & 1.67 & 4.09 & 2.50 & 1.82 & 0 \\
\hline 32.5 & 8.13 & 2.50 & 4.23 & 3.00 & 0.88 & 0 \\
\hline 37.5 & 7.31 & 2.50 & 4.33 & 2.92 & 4.17 & 1.67 \\
\hline 42.5 & 6.25 & 4.06 & 4.38 & 2.73 & 3.75 & 0.63 \\
\hline 47.5 & 7.50 & 5.00 & 2.50 & 2.78 & 2.08 & 4.17 \\
\hline 52.5 & 5.00 & 5.50 & 4.17 & 2.65 & 1.67 & 2.14 \\
\hline 57.5 & 0 & 4.50 & 5.00 & 4.09 & 2.00 & 1.25 \\
\hline 62.5 & 0 & 5.00 & 2.22 & 5.00 & 2.76 & 2.50 \\
\hline 67.5 & 0 & 5.00 & 0 & 4.44 & 0.80 & 0.49 \\
\hline 72.5 & 0 & 0 & 0 & 3.27 & 1.60 & 1.25 \\
\hline 77.5 & 0 & 0 & 0 & 3.38 & 1.35 & 1.44 \\
\hline 82.5 & 0 & 0 & 0 & 2.50 & 1.45 & 1.36 \\
\hline 87.5 & 0 & 0 & 0 & 3.00 & 1.73 & 0.91 \\
\hline 92.5 & 0 & 0 & 0 & 2.50 & 0.90 & 0.56 \\
\hline 97.5 & 0 & 0 & 0 & 0 & 0 & 0 \\
\hline
\end{tabular}

a geopotential height difference of more than $35 \mathrm{~m}$ above an altitude of $15 \mathrm{~km}$. A comparison between daytime and nighttime flights in the tropics revealed that the pressure difference was systematically larger in the day than at night at altitudes above $4.5 \mathrm{~km}$, the suggestion being that there was some effect of solar heating on the pressure measurements. The exact reason, however, is unclear.

The RS41 and RS92 temperature measurements in general agreed better than the combined uncertainties, but there were some noteworthy exceptions. One possible reason for the noteworthy discrepancies is the wet-bulbing effect described by Jensen et al. (2016). In a dry layer just above a saturated layer, the RS92 temperature sensor was cooled too much by evaporation. The RS41 temperature appeared to be less sensitive to this wet-bulbing effect. This phenomenon was confirmed in both the tropics and Arctic. During heavy rain and weak wind conditions, the stagnation of the balloon probably suppressed the ventilation around the temperature sensors, the result being an extreme temperature difference.

The median of the relative humidity differences at all altitudes was only a little more than $2 \%$ RH. However, there were quite large differences at an altitude of about $17 \mathrm{~km}$. These large differences occurred in the daytime around the tropical tropopause, where the temperature was below $-80^{\circ} \mathrm{C}$. The reason for this dry bias may be that there was some remnant of the error of the RS92 radiosonde solar radiation correction. The differences in humidity affected the calculation of CAPE, CIN, and PW, and we confirmed the daynight difference of these variables. We attempted to correct the RS92 relative humidity data obtained in the daytime during the MR15-04 cruise by using the CDF matching method, 
and the corrected RS92 relative humidity agreed well with the RS41 values.

Our results showed that measurements with the RS41 radiosonde satisfied the performance specifications of the manufacturer in most cases over both the tropical and polar oceans. The RS41 temperature and humidity sensors appeared to be unaffected by the solar radiation correction error and the wet-bulbing effect. Some concerns, however, do remain. Specifically, the reasons for the pressure bias in the upper layer and the two cases of extreme temperature discrepancies that occurred below an altitude of several hundred meters are unknown. Further experiments will be necessary to address these issues, and users should be cognizant of these concerns.

Data availability. The sounding dataset and the ship-observed surface meteorology are expected to be released just 2 years after the cruises (October 2017 for the MR15-03, and December 2017 for the MR15-04) from the website of the Data Research System for Whole Cruise Information (DARWIN) in JAMSTEC (http: //www.godac.jamstec.go.jp/darwin/e) in accord with the cruise data policy of JAMSTEC.

Author contributions. All co-authors contributed to designing the experiments and preparing for the observation cruises. YK, MK, and KO participated in the R/V Mirai cruises and carried out the radiosonde soundings. KO reprocessed the RS92 data. MK calculated CAPE, CIN, and PW. YK mainly analyzed the data and prepared the manuscript with contributions from all co-authors.

Competing interests. The authors declare that they have no conflict of interest.

Acknowledgements. The authors sincerely thank the captains, crews, and observation technicians of R/V Mirai and all colleagues who helped with the experiments. The authors are also grateful to Kunio Yoneyama of JAMSTEC for valuable advice, especially for advice concerning the humidity correction. This study was supported by the Japan Society for the Promotion of Science (JSPS) Grants-in-Aid for Scientific Research (A), (B), and (C) (KAKENHI) grant numbers 24241009, 16H04046, and 16K05563.

Edited by: Joanna Joiner

Reviewed by: three anonymous referees

\section{References}

Bodeker, G. E., Bojinski, S., Cimini, C., Dirksen, R. J., Haeffelin, M., Hannigan, J. W., Hurst, D. F., Leblanc, T., Madonna, F., Maturilli, M., Mikalsen, A. C., Philpona, R., Reale, T., Siedel, D. J., Tan, D. G. H., Thorne, P. W., Vömel, H., and Wang, J.: Reference upper-air observations for climate:
From concept to reality, B. Am. Meteorol. Soc., 97, 123-135, https://doi.org/10.1175/BAMS-D-14-00072.1, 2016.

Ciesielski, P. E., Johnson, R. H., and Wang, J: Correction of humidity biases in Vaisala RS80-H sondes during NAME, J. Atmos. Ocean. Tech., 26, 1763-1780, https://doi.org/10.1175/2009JTECHA1222.1, 2009.

Ciesielski, P. E., Chang, W.-M., Huang, S. -C., Johnson, R. H., Jou, B. J.-D., Lee, W.-C., Lin, P.-H., Liu, C.H., and Wang, J.: Quality-controlled upper-air sounding dataset for TiMREX/SoWMEX: Development and corrections, J. Atmos. Ocean. Tech., 27, 1802-1821, https://doi.org/10.1175/2010JTECHA1481.1, 2010.

Ciesielski, P. E., Yu, H., Johnson, R. H., Yoneyama, K., Katsumata, M., Long, C. N., Wang, J., Loehrer, S. M., Young, K., Williams, S. F., Brown, W., Braun, J., and Van Hove, T.: Quality-controlled upper-air sounding dataset for DYNAMO/CINDY/AMIE: Development and corrections, J. Atmos. Ocean. Tech., 31, 741-764, https://doi.org/10.1175/JTECH-D-13-00165.1, 2014.

Fujita, M., Kimura, F., Yoneyama, K., and Yoshizaki, M.: Verification of precipitable water vapor estimated from shipborne GPS measurements, Geophys. Res. Lett., 35, L13803, https://doi.org/10.1029/2008GL033764, 2008.

Inoue, J., Enomoto, T., and Hori, M. E.: The impact of radiosonde data over the ice-free Arctic Ocean on the atmospheric circulation in the Northern Hemisphere, Geophys. Res. Lett., 40, 864869, https://doi.org/10.1002/grl.50207, 2013.

Inoue, J., Yamazaki, A., Ono, J., Dethloff, K., Maturilli, M., Neuber, R., Edwards, P., and Yamaguchi, H.: Additional Arctic observations improve weather and sea-ice forecasts for the Northern Sea Route, Sci. Rep., 5, 16868, https://doi.org/10.1038/srep16868, 2015.

JAMSTEC: R/V Mirai Cruise Report MR15-03, Cruise Rep., Japan Agency for Marine-Earth Science and Technology, Yokosuka, Japan, available from: http://www.godac.jamstec.go.jp/catalog/ data/doc_catalog/media/MR15-03_leg1_all.pdf (last access: 10 July 2017), 297 pp., 2015.

JAMSTEC and BPPT: R/V Mirai Cruise Report MR1504, Cruise Rep., Japan Agency for Marine-Earth Science and Technology, Yokosuka, Japan, Agency for the Assessment and Application of Technology, Indonesia, available from: http://www.godac.jamstec.go.jp/catalog/data/doc_catalog/ media/MR15-04_all.pdf (last access: 10 July 2017), 241 pp., 2015.

Jauhiainen, H., Survo, P., Lehtinen, R., and Lentonen, J.: Radiosonde RS41 and RS92 key differences and comparison test results in different locations and climates. TECO-2014, WMO Technical Conference on Meteorological and Environmental Instruments and Methods of Observations, Saint Petersberg, Russian Federation, 7-9 July 2014, P3(16), 2014.

Jensen, M. P., Holdridge, D. J., Survo, P., Lehtinen, R., Baxter, S., Toto, T., and Johnson, K. L.: Comparison of Vaisala radiosondes RS41 and RS92 at the ARM Southern Great Plains site, Atmos. Meas. Tech., 9, 3115-3129, https://doi.org/10.5194/amt-9-31152016, 2016.

Kawai, Y., Tomita, H., Cronin, M. F., and Bond, N. A.: Atmospheric pressure response to mesoscale sea surface temperature variations in the Kuroshio Extension: In situ evidence, J. Geophys. Res.-Atmos., 119, 8015-8031, https://doi.org/10.1002/2013JD021126, 2014. 
Maturilli, M. and Kayser, M.: Arctic warming, moisture increase and circulation changes observed in the Ny-Ålesund homogenized radiosonde record, Theor. Appl. Climatol., https://doi.org/10.1007/s00704-016-1864-0, 2016.

Miloshevich, L. M., Vömel, H., Whiteman, D. N., and Leblanc, T.: Accuracy of assessment and correction of Vaisala RS92 radiosonde water vapor measurement, J. Geophys. Res., 114, D11305, https://doi.org/10.1029/2008JD011565, 2009.

Minobe, S. and Takebayashi, S.: Diurnal precipitation and high cloud frequency variability over the Gulf Stream and over the Kuroshio, Clim. Dynam., 44, 2079-2095, https://doi.org/10.1007/s00382-014-2245-y, 2015.

Motl, M.: Vaisala RS41 trial in the Czech Republic, Vaisala News, 192, 14-17, 2014.

Nuret, M., Lafore, J.-P., Bock, O., Guichard, F., Agusti-Panareda, A., N'Gamini, J.-B., and Redelsperger, J.-L.: Correction of humidity bias for Vaisala RS80-A sondes during the AMMA 2006 observing period, J. Atmos. Ocean. Tech., 25, 2152-2158, https://doi.org/10.1175/2008JTECHA1103.1, 2008.

Thorne, P. W., Parker, D. E., Tett, S. F. B., Jones, P. D., McCarthy, M., Coleman, H., and Brohan, P.: Revisiting radiosonde upper air temperatures from 1958 to 2002, J. Geophys. Res., 110, D18105, https://doi.org/10.1029/2004JD005753, 2005.

Vömel, H., Selkirk, H., Miloshevich, L., Valverde-Canossa, J., Valdés, J., Kyrö, E., Kivi, R., Stolz, W., Peng, G., and Diaz, J. A.: Radiation dry bias of the Vaisala RS92 humidity sensor, J. Atmos. Ocean. Tech., 24, 953-963, https://doi.org/10.1175/JTECH2019.1, 2007.
Wang, J., Zhang, L., Dai, A., Immler, F., Sommer, M., and Vömel, H.: Radiation dry bias correction of Vaisala RS92 humidity data and its impacts on historical radiosonde data, J. Atmos. Ocean. Tech., 30, 197-214, https://doi.org/10.1175/JTECH-D12-00113.1, 2013.

Yang, G.-Y. and Slingo, J.: The diurnal cycle in the tropics, Mon. Weather Rev., 129, 784-801, https://doi.org/10.1175/15200493(2001)129<0784:TDCITT>2.0.CO;2, 2001.

Yoneyama, K., Hanyu, M., Sueyoshi, S., Yoshiura, F., and Katsumata, M.: Radiosonde observation from the ship in the tropical region, Report of Japan Marine Science and Technology Center, available from: http://www.jamstec.go.jp/res/ress/yoneyamak/ PDFs/Yoneyama-etal_2002_JAMSTECR.pdf (last access: 10 July 2017), 45, 31-39, 2002.

Yoneyama, K., Fujita, M., Sato, N., Fujiwara, M., Inai, Y., and Hasebe, F.: Correction for radiation dry bias found in RS92 radiosonde data during the MISMO field experiment, SOLA, 4, 13-16, https://doi.org/10.2151/sola.2008-004, 2008.

Yu, H., Ciesielski, P. E., Wang, J., Kuo, H.-C., Vömel, H., and Dirksen, R.: Evaluation of humidity correction methods for Vaisala RS92 tropical sounding data, J. Atmos. Ocean. Tech., 32, 397411, https://doi.org/10.1175/JTECH-D-14-00166.1, 2015. 